\title{
ABDIC Regimen
}

National Cancer Institute

\section{Source}

National Cancer Institute. ABDIC Regimen. NCI Thesaurus. Code C9666.

A chemotherapy regimen consisting of bleomycin, dacarbazine, doxorubicin, lomustine and prednisone used for the treatment of relapsed or refractory Hodgkin lymphoma. 